
License. Which Permits unrestricted use, distrubution, and reproduction in any medium, provided the original work is properly cited

\title{
Uji Reliabilitas Sendai Framework for Disaster Risk Reduction Dalam Rehabilitasi Kawasan Ekonomi Khusus Tanjung Lesung
}

\author{
Karina Stefanie dan Natalia Yeti Puspita \\ Fakultas Hukum Universitas Katolik Indonesia Atma Jaya Jakarta Indonesia \\ Jln. Jenderal Sudirman 51, Jakarta Indonesia 12930 \\ stefaniekarina@gmail.com; natalia.yp@atmajaya.ac.id
}

Received: 18 September 2020; Accepted: 17 November 2020; Published: 16 Maret 2021

DOI: 10.20885/iustum.vol28.iss1.art10

\begin{abstract}
State has the main responsibility in any disaster management process. The Sendai Framework for Disaster Risk Reduction (SFDR) is an international disaster management agreement in a country which Indonesia also ratifies. The research objective is to determine how the reliability test of the SFDRR in the rehabilitation of the Tanjung Lesung Special Economic Zone (KEK) after the 2018 tsunami. This research is an empirical juridical study, primary data as the main data obtained from field research and interviews, as a complement, a literature study was conducted to obtain secondary data. The results of the study concluded that rehabilitation efforts based on the SFDRR had been carried out by the government but there were no direct coordination and communication between the government, KEK managers, local communities, and tourists.
\end{abstract}

Keywords: KEK Tanjung Lesung; reliabitlity test; rehabilitation; sendai framework for disaster risk reduction

Abstrak

Negara memiliki tanggung jawab utama dalam setiap proses penanggulangan bencana. Sendai Framework for Disaster Risk Reduction merupakan perjanjian internasional penanggulangan bencana di suatu negara dan Indonesia turut meratifikasinya. Tujuan penelitian adalah untuk mengetahui bagaimanakah uji reliabilitas Sendai Framework for Disaster Risk Reduction (SFDRR) dalam rehabilitasi Kawasan Ekonomi Khusus (KEK) Tanjung Lesung pasca tsunami 2018. Penelitian ini merupakan penelitian yuridis empiris, data primer sebagai data utama diperoleh dari penelitian lapangan dan wawancara, sebagai pelengkap dilakukan studi kepustakaan untuk memperoleh data sekunder. Hasil penelitian menyimpulkan bahwa upaya rehabilitasi berdasarkan SFDRR telah dilakukan oleh pemerintah tetapi belum terlihat koordinasi dan komunikasi yang terarah antara pemerintah, pengelola KEK, masyarakat sekitar, dan wisatawan

Kata-kata Kunci: Uji reliabilitas; sendai framework for disaster risk reduction; rehabilitasi; KEK Tanjung Lesung 


\section{Pendahuluan}

Indonesia merupakan negara kepulauan yang terletak di kawasan Cincin Api Pasifik (Pacific Ring of Fire) yaitu rangkaian jalur gunung api aktif yang tersebar di atas lempeng bumi ${ }^{1}$ dengan 127 gunung api aktif yang 76 diantaranya

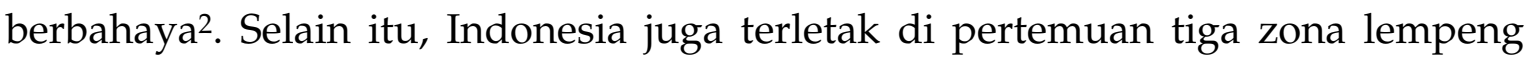
dunia yaitu lempeng Indo-Australia, Eurasia, dan Pasifik yang menyebabkan terjadinya gempa bumi baik tektonik maupun vulkanik akibat dari aktivitas antar lempeng. Kondisi alam inilah yang menyebabkan Indonesia menjadi salah satu negara yang rawan terhadap berbagai jenis bencana alam. Bencana alam merupakan peristiwa di luar kendali manusia yang dapat terjadi setiap saat dan menimbulkan berbagai kerugian baik materil maupun immateril bagi kehidupan makhluk hidup berupa kerusakan infrastruktur dan bangunan hingga merenggut nyawa manusia.

Berdasarkan hasil laporan dari Centre for Research on the Epidemiology of Disaster (CRED) di Jenewa Swiss, pada 24 Januari 2019 oleh Badan Perserikatan Bangsa-Bangsa Untuk Pengurangan Risiko Bencana (UNISDR), Indonesia menjadi salah satu negara dengan jumlah korban jiwa akibat bencana alam tertinggi di dunia sepanjang 2018 dengan total 4.814 korban jiwa $^{3}$. Selain itu, Badan Nasional Penanggulangan Bencana (BNPB) juga mencatat bahwa kerugian ekonomi yang diakibatkan oleh bencana alam di Indonesia pada 2018 mencapai lebih dari 100 juta triliun4. Tercatat hingga September 2019 telah terjadi 2.829 bencana di Indonesia yang didominasi oleh bencana hidrometeorologi seperti puting beliung, banjir, dan tanah longsor (sebesar 98\%), serta bencana geologi seperti gempa bumi, tsunami dan letusan gunung api (sebesar 2\%) namun kerugian yang ditimbulkan sangat besar. ${ }^{5}$ Tsunami merupakan salah satu

\footnotetext{
1 Aprilia Nurmawati, Analisis Pergerakan Magma Gunung Berapi dengan Menggunakan Diagram serta Estimasi Potensi: Volume Magma dengan Menggunakan Data Gravitasi, Universitas Gajah Mada, Yogyakarta, 2013, hlm. 1.

${ }^{2}$ Natalia Yeti Puspita, dkk, "Implementasi Hyogo Framework. Action di Indonesia dalam kaitannya dengan Mitigasi Bencana Alam di Kawasan Pariwisata (Studi kasus: Mitigasi Bencana Alam di Kawasan Wisata Pesisir Pantai Banten), Laporan Penelitian Lintas Fakultas, Fakultas Hukum dan Fakultas Ilmu Administrasi Bisnis dan Ilmu Komunikasi, Unika Atma Jaya Jakarta, 2019, hlm. 2.

${ }^{3}$ Ibid.

${ }^{4}$ Ibid., hlm. 3.

5 Kompas, "Sejak Januari - September 2019, 2.829 Bencana Terjadi di Indonesia", https://nasional.kompas.com/read/2019/10/03/10171591/sejak-januari-september-2019-2829-bencanaterjadi-di-indonesia, diakses 25 Oktober 2019.
} 
bencana geologi yang sering terjadi di Indonesia, berupa gelombang ombak laut besar akibat gempa dalam laut karena pergeseran lempeng yang dapat menimbulkan kerusakan dahsyat hingga korban jiwa dalam jumlah besar.

Selain kerugian sektor ekonomi, kerugian akibat bencana alam juga turut dirasakan sektor pariwisata di Indonesia yang tercatat hingga US\$ 1 miliar per 2018. Termasuk di dalamnya kerugian akibat bencana Tsunami yang terjadi di Kawasan Ekonomi Khusus (KEK) Tanjung Lesung, Kabupaten PandeglangBanten pada 22 Desember 2018. Tsunami ini terjadi karena adanya longsor bawah laut akibat erupsi Gunung Anak Krakatau. ${ }^{6}$

Proses penanggulangan bencana merupakan serangkaian kegiatan/tindakan yang dilakukan pada saat belum terjadi bencana (mitigasi bencana), pada saat terjadi bencana (tanggap darurat bencana), dan setelah terjadi bencana (rehabilitasi). Dalam penelitian ini lebih difokuskan pada fase rehabilitasi karena hal ini masih belum menjadi prioritas pemerintah terutama dalam sektor pariwisata. Adapun tahap rehabilitasi meliputi tindakan perbaikan fisik lokasi bencana serta perbaikan terhadap kesejahteraan sosial dan psikologis korban bencana atau trauma healing 7 .

Sampai saat ini, memang belum ada aturan internasional yang bersifat universal dan mengikat dalam penanggulangan bencana, akan tetapi terdapat sebuah panduan yang diakui oleh negara-negara dalam penanggulangan bencana di negaranya yaitu Sendai Framework for Disaster Risk Reduction 2015-2030 (SFDRR). SFDRR merupakan perjanjian internasional yang disepakati oleh 187 negara dalam Konferensi Pengurangan Risiko Bencana Persatuan Bangsa-Bangsa Ketiga pada 18 Maret 2015 di Sendai, Miyagi, Jepang. ${ }^{8}$ Dalam SFDRR dinyatakan bahwa negara memiliki peran yang sangat penting dalam hal terjadinya suatu bencana di negaranya dan merupakan kelanjutan dari Hyogo Framework for Action (HFA) 2005-2015. Indonesia merupakan negara pihak dalam SFDRR tersebut.

\footnotetext{
6 Tribun, "Bukan Gempa, Tsunami di Pantai Banten disebabkan 3 Hal : Gelombang Tinggi hingga Erupsi Gunung”, $\quad$ https://style.tribunnews.com/2018/12/23/bukan-gempa-tsunami-di-pantai-barat-bantendisebabkan-3-hal-gelombang-tinggi-hingga-erupsi-gunung, diakses 19 Oktober 2019.

7 Qomarun, "Model Complement and Focus dalam Penanganan Pasca Bencana Tahap Rehabilitasi (Studi Kasus pada peristiwa Peristiwa Gempa Bumi di Klaten 27 Mei 2006)", Jurnal Warta, Vol. 10, No. 1, 2007, hlm. 45.

8 UN Office for Disaster Risk Reduction, Sendai Framework for Disaster Risk Reduction 2015-2030, https://www.preventionweb.net/sendai-framework/sendai-framework-for-drr (ditelusuri 5 Desember 2019).
} 
SFDRR disusun untuk memastikan bahwa negara-negara atau pemangku kepentingan melakukan keberlanjutan dari HFA dan membuat berbagai inovasi baru dalam penanggulangan bencana. Perubahan terpenting dari HFA ke SFDRR yaitu pada manajemen pengurangan risiko bencana dan penanganan perubahan iklim sebagai faktor pendorong terjadinya risiko bencana serta menghasilkan prinsip panduan termasuk tanggung jawab negara dalam mencegah dan mengurangi risiko bencana. Sehingga, negara anggota secara bersama-sama diharapkan dapat mengatasi tantangan global seperti kemiskinan, perubahan iklim dan degradasi lingkungan serta memberikan kemakmuran, perdamaian dan keadilan.

SFDRR memiliki beberapa indikator dalam proses penanggulangan bencana yaitu meningkatkan pemahaman terhadap risiko bencana, memperkuat tata cara pelaksanaan risiko bencana dalam pengelolaan risiko bencana, melakukan investasi pengurangan risiko bencana untuk ketangguhan, meningkatkan kesiapsiagaan bencana, serta membangun lebih baik dalam upaya pemulihan, rehabilitasi dan rekonstruksi. Oleh karena itu, perlu dilakukan uji reliabilitas terhadap SFDRR di KEK Tanjung Lesung untuk mengetahui ketepatan dan pelaksanaan SFDRR sebagai instrumen dalam pengurangan risiko bencana di negara anggota termasuk di dalamnya Indonesia. Uji reliabilitas adalah pengujian terhadap ketepatan suatu instrumen terhadap data yang dikemukakan dari keadaan sebenarnya di masyarakat dengan ketelitian dalam pengungkapannya sehingga hasil penelitian dan fakta di lapangan yang diperoleh dapat diinterpretasikan dan diinformasikan secara tepat sesuai dengan keadaan sesungguhnya. ${ }^{9}$

\section{Rumusan Masalah}

Berdasarkan hal tersebut di atas maka rumusan masalah penelitian dalam tulisan ini adalah bagaimanakah uji reliabilitas Sendai Framework for Disaster Risk Reduction 2015-2030 (SFDRR) dalam proses rehabilitasi KEK Tanjung Lesung pasca Tsunami 2018?

${ }^{9}$ Dyah Budiastuti dan Agustinus Bandur, Validitas dan Reliabilitas Penelitian - Dilengkapi Analisis dengan NVIVO, SPSS, dan Amos, Penerbit Mitra Wacana Media, Jakarta, 2018, hlm. 196-197. 


\section{Tujuan Penelitian}

Adapun tujuan penelitian ini adalah untuk mengetahui uji reliabilitas atau penerapan SFDRR dalam rehabilitasi KEK Tanjung Lesung pasca Tsunami 2018 oleh Pemerintah Indonesia.

\section{Metode Penelitian}

Penelitian ini merupakan penelitian normatif-empiris yaitu mengenai implementasi berlakunya suatu aturan ketentuan hukum normatif atau hukum positif berupa peraturan perundang - undangan maupun perjanjian internasional pada peristiwa hukum tertentu yang terjadi di masyarakat. Dalam penelitian ini, peneliti hendak mengetahui uji reliabilitas atau penerapan Sendai Framework for Disaster Risk Reduction 2015-2030 sebagai perjanjian internasional dalam rehabilitasi KEK Tanjung Lesung pasca tsunami 2018 oleh Indonesia. Data primer diperoleh melalui penelitian ke lapangan dan wawancara terhadap narasumber yaitu BPBD Provinsi Banten dan Kabupaten Pandeglang, Dinas Pariwisata Provinsi Banten, Pengelola KEK Tanjung Lesung, wisatawan, dan juga masyarakat di sekitar lokasi. Adapun untuk menunjang data primer, peneliti menggunakan data sekunder yaitu data kepustakaan berupa peraturan perundang-undangan yang berlaku, perjanjian internasional yang berkenaan dengan penelitian, buku, jurnal, dan situs internet. Analisis data yang digunakan adalah kualitatif yaitu analisis yang menghasilkan suatu uraian mendalam ke dalam tulisan dengan memilah data yang telah dikelola dan ditemukan pola penting yang kemudian disampaikan ke khalayak luas.

\section{Hasil Penelitian dan Pembahasan}

Sendai Framework for Disaster Risk Reduction sebagai Sebuah Perjanjian Internasional

Dalam Pasal 2 ayat (1) butir a Konvensi Wina 1969 dijelaskan bahwa perjanjian internasional adalah suatu persetujuan yang dibuat antara negara dalam bentuk tertulis dan diatur oleh hukum internasional, baik dalam instrumen tunggal atau dua atau lebih instrumen yang berkaitan dan apapun nama yang 
diberikan padanya. ${ }^{10}$ Mulanya perjanjian internasional hanya sebagai hukum kebiasaan hingga diselenggarakannya konferensi internasional di Wina pada 22 Mei 1969 untuk mengkodifikasi hukum kebiasaan tersebut menjadi peraturan tertulis yang menghasilkan Vienna Convention on the Law of Treaties atau Konvensi Wina 1969 tentang Hukum Perjanjian yang ditandatangani pada 23 Mei 1969 dan mulai berlaku pada 27 Januari $1980 .{ }^{11}$ Meskipun Indonesia tidak meratifikasi Konvensi Wina 1969, namun ketentuan yang terdapat di dalamnya menjadi pedoman bagi Indonesia yang telah diundangkan dalam Undang-Undang Nomor 24 Tahun 2000 tentang Perjanjian Internasional dan diterapkan menjadi hukum positif Indonesia.

Hukum Internasional tidak mengatur secara spesifik pengklasifikasian istilah - istilah dalam perjanjian internasional karena penamaan tertentu hanya untuk menunjukkan keinginan dan maksud dari pihak terkait, meskipun istilah yang digunakan beragam. Beberapa istilah yang sering digunakan untuk menyebut suatu perjanjian internasional yaitu antara lain Traktat (treaty), Konvensi (Convention), Deklarasi (declaration), Statuta (statute), Piagam (charter), Persetujuan (agreement), Perjanjian, Pakta (pact), Protokol (protocol), Memorandum of Understanding (MOU), dan Modus Vivendi. ${ }^{12}$

SFDRR diadopsi dan disepakati oleh 187 negara dalam Konferensi Pengurangan Risiko Bencana Persatuan Bangsa-Bangsa Ketiga pada 18 Maret 2015 di Sendai, Miyagi, Jepang. ${ }^{13}$ Kerangka kerja ini disusun untuk HFA (Hyogo Framework for Action) yang telah berakhir di 2005 dengan membuat berbagai inovasi dengan konsultasi dan negosiasi. Tindak lanjut dari Kerangka Kerja Sendai ini dilakukan oleh Jepang dan negara-negara ASEAN dengan disepakatinya Revised Implementation Plan of The Vision Statement on ASEAN Japan Friendship and Cooperation: Shared Vision, Shared Identity, Shared Future yang salah satu fokus kerjasamanya dalam penanggulangan bencana, tanggap darurat dan pengurangan kerugian akibat bencana berdasarkan SFDRR ini.

${ }^{10}$ Vienna Convention on the Law of Treaty 1969, Article. 2.

${ }^{11}$ Devita Retno, "Sejarah Perjanjian Internasional Konvensi Wina 1969", https://sejarahlengkap.com/dunia/sejarah-perjanjian-internasional, diakses tanggal 23 November 2019.

12 I Wayan Parthiana, Hukum Perjanjian Internasional - Bagian I, Mandar Maju, Bandung, 2018, hlm. 27-34.

${ }^{13}$ UN Office for Disaster Risk Reduction, Loc. Cit. 
Sendai Framework for Disaster Risk Reduction (SFDRR) termasuk dalam kategori perjanjian internasional karena merupakan pernyataan sepakat dari para negara, meskipun dalam bentuk panduan atau guideline yang bersifat umum untuk melakukan pencegahan dan pengurangan risiko bencana. ${ }^{14}$ Kerangka kerja ini merupakan kesepakatan sukarela yang tidak mengikat secara yuridis (nonlegally binding) sehingga tidak ada konsekuensi hukum yang timbul bagi negara anggota yang tidak menerapkan atau menaati Kerangka Kerja Sendai ini.

SFDRR tidak memuat ketentuan atau pasal terkait saat mulai berlakunya sehingga berdasarkan Pasal 24 ayat (2) Konvensi Wina 1969 maka SFDRR ini mulai berlaku sejak para pihak menyatakan kesepakatan atau persetujuannya. ${ }^{15}$ Namun, perlu diingat bahwa pasal ini bersifat sebagai pedoman saja sebab pada praktiknya negara - negara memiliki kebebasan penuh untuk menentukan sendiri saat dan cara mulai berlakunya perjanjian.

\section{Isi Sendai Framework for Disaster Risk Reduction (SFDRR)}

Terdapat tujuh target global dalam SFDRR ini yaitu: (1) Mengurangi kematian akibat bencana global hingga rata-rata per 100.000 tingkat kematian pada 2020-2030; (2) Mengurangi jumlah orang yang terkena dampak global hingga rata-rata 100.000 pada 2030; (3) Mengurangi kerugian ekonomi akibat bencana dalam kaitannya dengan Produk Domestik Bruto (PDB) secara global pada 2030; (4) Mengurangi kerusakan infrastruktur akibat bencana dan gangguan layanan dasar lainnya; (5) Meningkatkan jumlah negara dengan strategi dan rencana Pengurangan Risiko Bencana Nasional dan Lokal pada 2020; (6) Meningkatkan kerjasama internasional dengan negara-negara berkembang untuk mendukung dan memadai keberlanjutan tindakan kerangka dari kerangka kerja ini hingga pada 2030; dan (7) Meningkatkan ketersediaan dan akses ke sistem peringatan dini atau multi bahaya dan informasi atas risiko bencana kepada orang-orang pada $2030 .{ }^{16}$

\footnotetext{
${ }^{14}$ UN Office for Disaster Risk Reduction, Loc. Cit.

15 Permanent Mission of the Republic of Indonesia, Indonesia Berbasil Upayakan Pengakuan Konsep Negara Kepulauan dalam Rangka Kerangan Pengurangan Risiko Bencana, https://mission-indonesia.org/2015/03/19/ indonesia-berhasil-upayakan-pengakuan-konsep-negara-kepulauan-dalam-kerangka-pengurangan-resiko-bencana$\mathrm{pbb/}$, diakses tanggal 20 April 2020.

${ }^{16}$ UN Office for Disaster Risk Reduction, Op. Cit., hlm. 15.
} 
Adapun empat prioritas untuk Aksi SFDRR yaitu sebagai berikut: (1) Memahami risiko bencana melalui kebijakan berdasarkan pemahaman terkait kerentanan, kapasitas, karakteristik bahaya dan lingkungan; (2) Penguatan tata kelola risiko dengan mendorong kerjasama antar lembaga untuk pelaksanaan mekanisme pengurangan risiko bencana (PRB) dengan strategi dan rencana tugas di semua sektor; (3) Investasi PRB untuk resiliensi, dengan dilakukannya investasi publik dan swasta untuk tindakan struktural dan nonstruktural dalam meningkatkan ketahanan dan pendorong inovasi; dan (4) Meningkatkan kesiapsiagaan bencana untuk respon yang efektif dan untuk "membangun kembali dengan lebih baik" dalam pemulihan, rehabilitasi dan rekonstruksi. ${ }^{17}$ Prioritas tersebut dalam dilihat dalam tabel berikut ini.

Tabel

Tindakan Prioritas ${ }^{18}$

\begin{tabular}{|c|c|c|c|}
\hline $\begin{array}{l}\text { Mendorong } \\
\text { pengumpulan, } \\
\text { manajemen dan } \\
\text { akses ke informasi } \\
\text { risiko } \\
\text { Gunakan dasar, data } \\
\text { berbasis lokasi } \\
\text { Statistik lokasi dan } \\
\text { kerugian } \\
\text { Mengoptimalisasika } \\
\text { n IPTEK } \\
\text { Gunakan informasi } \\
\text { risiko untuk }\end{array}$ & $\begin{array}{l}\text { Penguatan } \\
\text { kelola risiko } \\
\text { tata kelola yang } \\
\text { diperlukan untuk } \\
\text { mendorong } \\
\text { kerjasama } \\
\text { kemitraan, } \\
\text { mekanisme, } \\
\text { lembaga, untuk } \\
\text { pelaksanaan } P R B \mathcal{E} \\
\text { SD. }\end{array}$ & $\begin{array}{l}\text { asi PRB } \\
\text { Resiliensi } \\
\text { si publik } \\
\text { dalam } \\
\text { ral dan } \\
\text { uktural } \\
\text { katkan } \\
\text { an sebagai } \\
\text { ong } \\
\text { buhan dan } \\
\text { aan } \\
\text { an kerja } \\
\text { lokasikan }\end{array}$ & $\begin{array}{l}\text { erkuat } \\
\text { iagaan, } \\
\text { han dingkatan } \\
\text { atan untuk } \\
\text { asinya ke } \\
\text { ngunan. } \\
\text { ban dan } \\
\text { kan, } \\
\text { aa, } \\
\text { am } \\
\text { e-centred, } \\
\text { hazard, } \\
\text { an \& EWS } \\
\text { romosikan } \\
\text { anan } \\
\text { rakat, } \\
\text { an } \\
\text { truktur }\end{array}$ \\
\hline
\end{tabular}

${ }^{17}$ Ibid, hlm. 15-16.

18 BNPB, Kerangka Kerja Sendai untuk Pengurangan Risiko Bencana 2015-2030, Planas PRB, 2015, hlm. ii. 


\begin{tabular}{|c|c|c|c|}
\hline $\begin{array}{l}\text { kebijakan } \\
\text { pembangunan dan } \\
\text { PRB }\end{array}$ & $\begin{array}{l}\text { - Memberdayakan } \\
\text { daerah } \\
\text { - Mempromosikan } \\
\text { kebijakan, standar, } \\
\text { kemitraan }\end{array}$ & $\begin{array}{l}\text { standar, } \\
\text { kesehatan, jaring } \\
\text { pengaman sosial, } \\
\text { pengungsian } \\
\text { - Mengintegrasika } \\
\text { n PRB dalam } \\
\text { instrumen fiskal } \\
\text { \& keuangan dan } \\
\text { menggali risk } \\
\text { sharing \& } \\
\text { transfer } \\
\text { - Meningkatkan } \\
\text { ketahanan bisnis } \\
\text { - Melindungi mata } \\
\text { pencaharian, } \\
\text { pariwisata, dll } \\
\end{array}$ & $\begin{array}{l}\text { pemulihan } \\
\text { pendanaan, } \\
\text { koordinasi, } \\
\text { prosedur } \\
\text { - Mengembangka } \\
\text { n hukum, } \\
\text { panduan, } \\
\text { prosedur, } \\
\text { mekanisme }\end{array}$ \\
\hline
\end{tabular}

Berkaitan dengan hal tersebut dapat diketahui bahwa SFDRR mengatur terkait pemulihan suatu wilayah pasca bencana dengan rehabilitasi dan rekonstruksi untuk mencegah terjadinya resiko dari bencana baru dan membangun kembali wilayah tersebut menjadi lebih baik dari sebelumnya dengan adanya koordinasi dan prosedur.

\section{SFDRR sebagai Aturan Internasional tentang Penanggulangan Bencana Alam}

Bencana alam menjadi isu yang masih menjadi masalah krusial bagi masyarakat dunia karena menjadi ancaman yang tidak dapat diprediksi oleh negara manapun kapan terjadinya. Peristiwa bencana menjadi permasalahan yang telah melanda setiap benua di dunia setidaknya sejak 1994-2013. Dalam kurun waktu tersebut, tercatat sebanyak 2.778 kali bencana alam yang terjadi di kawasan Asia. ${ }^{19}$ Setelah banyaknya fenomena bencana alam yang terjadi, masyarakat internasional sadar akan pentingnya regulasi terkait bencana alam agar dapat membantu negara-negara di dunia dalam mencegah, menyiapkan diri, dan menanggulangi bencana. Berbagai perjanjian internasional yang dibuat berlandaskan pada pengalaman yang mereka peroleh selama menanggulangi bencana. Beberapa peraturan internasional yang mengatur mengenai penanggulangan bencana alam yaitu:

${ }^{19}$ Natalia Yeti Puspita, "Tanggung Jawab Negara untuk Menerima Bantuan Kemanusiaan saat Tanggap Darurat Bencana Alam”, Jurnal Masalah-Masalab Hukum, Jilid 44 No.22, 2015, hlm. 208. 
1. Convention establishing an international relief union of 1927;

2. Inter-American Convention to Facilitate Disaster Assistance of 1991;

3. The Principles and Rules of Red Cross and Red Crescent in Disaster Relief as amended in 1995;

4. The Tampere Convention on the Provisions of Telecommunication Resources for Disaster Mitigation and Relief Operations of 1998;

5. The "Seville Agreement" on the Organization of International Activities of the Component of the International Red Cross and Red Crescent Movement;

6. ASEAN Agreement on Disaster Management and Emergency Response 2005;

7. The Supplementary measures to enhance the implementation of the Seville Agreement of 2005;

8. The Hyogo Framework for Action of 2005;20

9. IASC Operational Guidelines on Human Rights and Natural Disasters (2006); 21 dan

10. Sendai Framework for Disaster Risk Reduction (2015).

SFDRR bersifat soft law karena memuat komitmen atau kesepakatan para pihak untuk pencegahan dan pengurangan risiko bencana yang aturannya tidak mengikat negara anggota (non-legally binding). Walaupun hanya sebagai guideline yang bersifat soft law atau himbauan, akan tetapi dengan berdasarkan Bahrain case yang menjelaskan bahwa untuk menetapkan suatu perjanjian internasional, tidak harus dilihat dari namanya, namun lebih melihat dari isi atau substansinya, maka SFDRR ini dapat menjadi pondasi dalam pengurangan risiko bencana oleh negara-negara mengingat substansinya yang penting terkait dengan pengurangan risiko bencana.

SFDRR ini dapat diberlakukan di suatu negara dengan melalui mekanisme hukum adopsi atau transformasi. Seperti yang kita ketahui Penerapan hukum internasional dalam hukum nasional suatu negara yang bersangkutan tidaklah selalu sama. Beberapa negara mengimplementasikannya dengan proses ratifikasi (ratification), penandatanganan (signature) atau lainnya sesuai dengan Konvensi Wina 1969. Terdapat dua teori yang memberikan pembahasan mengenai penerapan hukum internasional dalam hukum nasional yaitu teori monisme dan teori dualisme. Teori monisme menganggap bahwa hukum internasional dan hukum nasional merupakan satu kesatuan perangkat hukum yang terbagi atas dua paham yaitu paham monisme dengan primat hukum nasional yang menganggap

\footnotetext{
${ }^{20} \mathrm{I}$ bid., hlm. 212.

${ }^{21}$ Ibid., hlm. 213.
} 
bahwa yang utama adalah hukum nasional, dan sebaliknya dalam paham monisme dengan hukum internasional yang utama adalah hukum internasional. ${ }^{22}$ Sedangkan teori dualisme yaitu teori yang menganggap bahwa hukum nasional dan hukum internasional merupakan perangkat hukum yang terpisah. Teori ini tidak mengenal adanya persoalan hirarki karena hakikatnya kedua perangkat hukum ini tidak bergantung satu sama lain atau terlepas satu sama lain.

Hingga saat ini banyak negara yang telah menerapkan SFDRR dan menjadikannya sebagai panduan bagi pengaturan penanggulangan bencana di negaranya. Negara-negara anggota tersebut sadar bahwa panduan ini membantu negara terkait untuk mengurangi risiko akibat bencana yang seringkali menyebabkan kerugian ekonomi dan banyaknya korban jiwa. Dari segi strukturnya, SFDRR dirancang untuk menciptakan aturan baru dan memperbaharui praktik yang sudah ada dalam hal pengurangan risiko bencana yang telah diatur sebelumnya dalam Hyogo Framework for Action.

\section{Keikutsertaan Indonesia dalam SFDRR}

Indonesia merupakan salah satu negara yang meratifikasi hasil Konferensi Dunia tentang Pengurangan Bencana Kedua, yaitu Hyogo Framework for Action (HFA) yang berakhir di 2015 dan digantikan oleh SFDRR yang berlaku hingga 2030 mendatang. ${ }^{23}$ Sejak saat itu, regulasi Indonesia turut dipengaruhi oleh HFA sebagai panduan umum dalam membuat, mengatur dan melaksanakan kebijakan penanggulangan bencana di Indonesia. Pengembangan dan penerapan upaya penanggulangan bencana telah disusun oleh Indonesia sejak mengadopsi HFA maupun SFDRR ke dalam kerangka hukum yang cukup kuat dan komprehensif yang dibuktikan dengan ditetapkannya Undang-Undang Nomor 24 Tahun 2007 tentang Penanggulangan Bencana dan Peraturan Pemerintah Republik Indonesia Nomor 21 Tahun 2008 tentang Penyelenggaraan Penanggulangan Bencana, serta Peraturan Presiden Republik Indonesia Nomor 8 Tahun 2008 tentang Badan Nasional Penanggulangan Bencana. Rangkaian peraturan lainnya yang kemudian

\footnotetext{
22 Y. Peryogawati, Monisme dan Dualisme Hukum Internasional, Fakultas Hukum Universitas Padjajaran, Bandung, 2016, hlm. 4.

${ }^{23}$ European Civil Protection and Humanity Aid Operations, Sendai Framework for Disaster Risk Reduction 2015-2030, https://ec.europa.eu/echo/partnerships/relations/european-and-international-cooperation/sendaiframework-disaster-risk-reduction_en, diakses tanggal 4 Desember 2019.
} 
bermunculan di tahun-tahun berikutnya juga turut menjelaskan ketentuan mengenai tanggung jawab pemerintah pusat dan daerah, hak dan kewajiban masyarakat, peran suatu lembaga, tahap-tahap tambahan serta bantuan keuangan untuk penanggulangan bencana.

Selain dengan regulasi, komitmen Indonesia dalam menerapkan SFDRR juga dilakukan dengan meningkatkan kerjasama internasional untuk dukungan yang memadai dan berkelanjutan sebagai bentuk implementasi salah satu prioritas aksi Kerangka Kerja Sendai. Dalam pertemuan Global Platform for Disaster Risk Reduction (GPDRR) 2019 di Jenewa, Jusuf Kalla selaku wakil presiden saat itu (2014-2019) dan perwakilan Indonesia menyampaikan bahwa Indonesia telah melakukan berbagai kerjasama dengan antar pemangku kepentingan dan pemerintah untuk membuat rencana pembangunan yang mencakup pengurangan risiko bencana dan membuat rencana pembangunan berjangka menengah dan panjang. ${ }^{24}$ Kerjasama tersebut diantaranya seperti Kerangka Kerja Sama Selatan-Selatan dan Kerjasama Triangular (KSST) yaitu bentuk kerjasama antar negara berkembang. Partisipasi aktif Indonesia dalam KSST ini perwujudan dari amanat UUD NRI 1945 tentang kebijakan politik luar negeri Indonesia dan pelaksanaan hubungan internasional yang bebas dan aktif. Kerjasama tersebut dilakukan dengan berbagai negara seperti Fiji, India, Australia, Korea Selatan, Selandia Baru, Swiss hingga Amerika Serikat dan negara ASEAN lainnya. ${ }^{25}$

\section{Uji Reliabilitas Sendai Framework for Disaster Risk Reduction 2015-2030 (SFDRR) dalam Rehabilitasi Kawasan Wisata Tanjung Lesung Pasca Tsunami 2018}

Seperti yang sudah dikemukakan dalam bagian pendahuluan, uji reliabilitas yang dimaksud dalam tulisan ini adalah sebuah pengujian dengan bentuk analisis hukum untuk melihat ketepatan penerapan SFDRR terhadap rehabilitasi KEK Tanjung Lesung oleh Indonesia dengan mengemukakan fakta sebenarnya di lapangan.

\footnotetext{
${ }^{24}$ Fauziah Mursid, JK Paparkan Komitmen Indonesia Kurangi Risiko Bencana, https://nasional.republika.co.id/berita/prmlpu335/jk-paparkan-komitmen-indonesia-kurangi-risiko-bencana, diakses 3 April 2020.

${ }^{25}$ Kementerian Kelautan dan Perikanan Republik Indonesia, Kontribusi Indonesia dalam Kerja Sama Global Pengurangan Risiko Bencana diakui Dunia, https://kkp.go.id/artikel/8739-bengkel-bergerak-bantu-pulihkan-geliatnelayan-terdampak-bencana, diakses 1 Maret 2020
} 


\section{Kondisi Geografis KEK Tanjung Lesung}

Kawasan Ekonomi Khusus (KEK) Tanjung Lesung merupakan salah satu kawasan wisata di Pesisir Banten yang memiliki keindahan alam berupa pantai yang indah. Kawasan ini terletak di ujung barat Pulau Jawa, tepatnya di Desa Tanjung Jaya, Kecamatan Panimbang Kabupaten Pandeglang, Provinsi Banten yang menghadap ke Gunung Anak Krakatau. KEK Tanjung Lesung merupakan KEK Pariwisata pertama dan telah diresmikan pada Februari 2015. Jarak tempuh dari Jakarta menuju KEK Tanjung Lesung membutuhkan waktu sekitar 3,5 jam menggunakan transportasi darat. Luas area dari KEK Tanjung Lesung yaitu seluas 1.500 ha.

Batas - batas dari KEK Tanjung Lesung yaitu di sebelah Utara, Selatan dan Timur berbatasan dengan Selat Sunda dan sebelah Barat berbatasan dengan desa Tanjung Jaya. Panjang garis pantai dari KEK Tanjung Lesung ini mencapai 15 km. Hal - hal tersebut kemudian yang membuat KEK Tanjung Lesung dinominasikan sebagai Kawasan "10 Bali Baru" oleh Kementerian Pariwisata dan Budaya Indonesia dan salah satu dari 50 destinasi Pariwisata Nasional hingga menduduki peringkat ke 88 kategori Kawasan Strategis Pariwisata Nasional bersama dengan Taman Nasional Ujung Kulon. ${ }^{26}$ Berikut adalah peta lokasi KEK Tanjung Lesung.

Gambar

Peta Kawasan Ekonomi Khusus Tanjung Lesung27

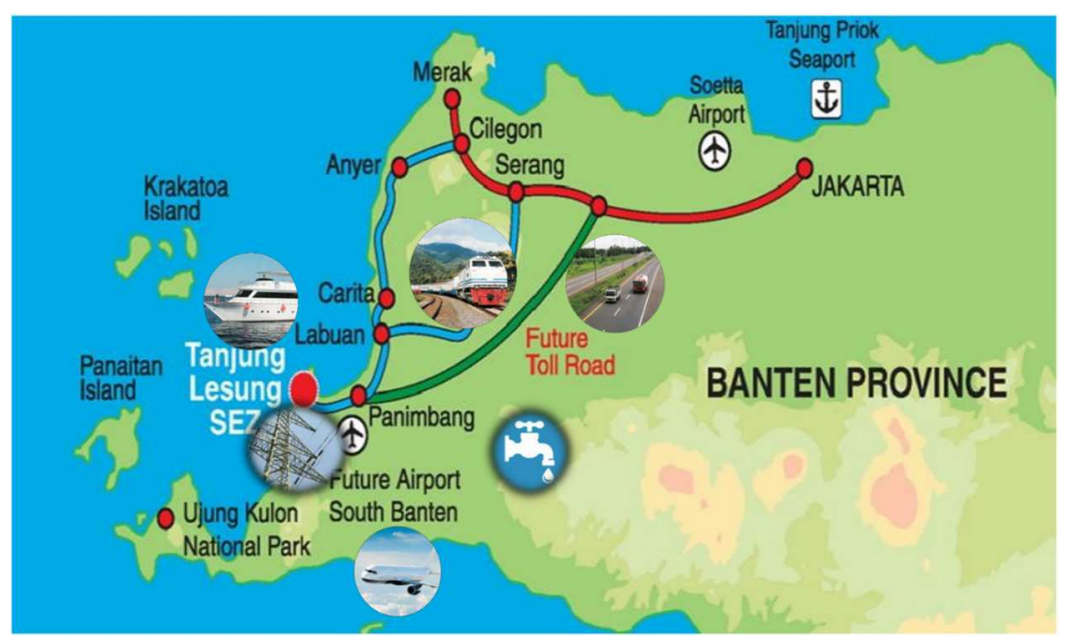

${ }^{26}$ Yeremia Jonathan Jemadu, Kajian Portofolio Kawasan Ekonomi Khusus Pariwisata Tanjung Lesung, Banten, Sekolah Tinggi Pariwisata, Bandung, 2016, hlm. 2.

27 Dinas Pariwisata Propinsi Banten, Power Point Pengembangan Kawasan Ekonomi Khusus Tanjung Lesung Ditinjau dari Perspektif Pengembangan SDM dan Pariwisata, 2018. 
Keberadaan kawasan ini dilandasi oleh beberapa peraturan yaitu: 1) Undang-Undang Nomor 39 Tahun 2009 tentang Kawasan Ekonomi Khusus; 2) PP Nomor 26 Tahun 2012 tentang Kawasan Ekonomi Khusus Tanjung Lesung; 3) Keputusan Gubernur Banten No. 505/Kep.587-Huk/2014 tentang Penetapan Administrator KEK Tanjung Lesung.

Saat ini Kawasan Ekonomi Khusus Tanjung Lesung berada di bawah pengelolaan Administrator KEK Tanjung Lesung berdasarkan Peraturan Daerah Kabupaten Pandeglang Nomor 2 Tahun 2014 dan Badan Usaha KEK Tanjung Lesung yaitu PT Banten West Java (BWJ) Tourism Development, anak usaha PT Jababeka Tbk. berdasarkan SK Bupati Pandeglang No. 556/KEP.173-Huk/2012 Tahun 2012.

\section{Kronologi Kejadian Tsunami di KEK Tanjung Lesung}

Beberapa bulan sebelum tsunami Selat Sunda 2018 terjadi, Gunung Anak Krakatau telah menunjukkan adanya aktivitas yang cukup aktif. Tercatat pada 21 Desember 2018, Pusat Vulkanologi dan Mitigasi Bencana Geologi (PVMBG) mendeteksi bahwa Gunung Anak Krakatau menyemburkan abu vulkanik setinggi kurang lebih 400 meter di atas puncak dan berada pada status waspada. Kemudian pada 22 Desember 2018, BMKG (Badan Meteorologi, Klimatologi dan Geofisika) memberikan peringatan bahwa akan adanya gelombang tinggi dengan potensi tsunami sejak 22 Desember 2018 pukul 07.00 WIB hingga 25 Desember pukul 07.00 WIB di wilayah perairan Selat Sunda dengan ketinggian 1,5 - 2,5 meter. ${ }^{28}$ Peringatan akan adanya gelombang tinggi tersebut terjadi pada 22 Desember 2018 sekitar pukul 20.56 WIB yang diawali erupsi oleh Gunung Anak Krakatau. Namun, sistem gempa BMKG tidak mendeteksi erupsi tersebut secara otomatis karena signal getaran yang dapat dideteksi adalah sinyal getaran untuk gempa bumi tektonik sedangkan aktivitas yang melanda Selat Sunda adalah akibat dari aktivitas vulkanik. ${ }^{29}$

Sekitar pukul 21.03 WIB, petugas Pusat BMKG mendapat laporan bahwa terjadi air laut pasang yang tidak normal di wilayah Banten dan Lampung yang

${ }^{28}$ Kompas, "Kronologi Tsunami di Banten versi BMKG" https://nasional.kompas.com/read/2018/ 12/23/09273881/kronologi-tsunami-di-banten-versi-bmkg?page=all diakses 30 Maret 2020.

${ }^{29}$ Bapak Surya Darmawan, Ketua LAKSA BPBD Pandeglang, Wawancara dengan Kepala BPBD Kabupaten Pandeglang, 29 Oktober 2019. 
akhirnya membuat BMKG melakukan Checking Marigram Tidegauge Badan Informasi Geospasial (BIG). Dari hasil pengecekan tersebut, pada pukul 21.27 WIB tercatat adanya erupsi dari Anak Gunung Krakatau dan menunjukkan adanya kenaikan muka air pantai di pesisir barat Banten yang setelah dianalisis gelombang tersebut adalah gelombang tsunami. Sehingga, pada hari yang sama BMKG Provinsi Banten menyampaikan telah terjadi tsunami di wilayah Banten dan Lampung yang bukan disebabkan gempa bumi tektonik serta bertepatan dengan adanya bulan purnama pada 21-25 Desember 2018. Pada keesokan harinya (23/12) pukul 14.40 WIB, BMKG memastikan bahwa pusat getaran berada di Anak Gunung Krakatau yang letaknya di 115,46 BT- 6.10 LS dengan kedalaman $1 \mathrm{~km}$.

Daerah yang terdampak paling parah dari bencana Tsunami ini adalah beberapa daerah pesisir yaitu kabupaten Pandeglang, Kabupaten Serang, Kabupaten Lampung Selatan dan Kabupaten Tanggamus. Kabupaten Pandeglang menjadi wilayah yang terimbas paling parah yang terdiri atas sebagian besar adalah kawasan wisata seperti Pantai Carita, Pantai Tanjung Lesung, Pantai Teluk Lada, Pantai Panimbang dan Pantai Sumur yang menjadi destinasi yang sering dikunjungi wisatawan dan pada hari terjadinya kejadian terdapat sebuah acara musik yang diselenggarakan di KEK Tanjung Lesung tersebut. ${ }^{30}$ Bencana ini mengakibatkan timbulnya korban jiwa sebanyak 373 orang meninggal dunia, 1.459 terluka dan 128 orang hilang serta 5.665 orang lainnya mengungsi yang kebanyakan dari korban yang tewas adalah wisatawan. Selain korban jiwa, kerugian fisik akibat tsunami ini meliputi 681-unit rumah rusak, 69 hotel dan villa rusak, 420 unit perahu dan kapal rusak, 60 unit warung dan toko rusak serta 133 unit kendaraan rusak. ${ }^{31}$ Fasilitas sarana dan prasarana umum lainnya yang terdampak yaitu sebanyak 150 unit gardu listrik padam dan akses beberapa jalan serta jembatan sempat tertutup.

${ }^{30}$ Badan Penanggulangan Bencana Daerah Pandeglang, Dinas Pariwisata Provinsi Banten, Presentasi atau FGD terkait Penanganan Bencana akibat Tsunami Selat Sunda di Banten, 30 Januari 2020.

31 Badan Nasional Penanggulangan Bencana, "Tim SAR Gabungan Terus Menemukan Korban Tsunami Selat Sunda : 373 Meninggal Dunia, 1.459 Luka-Luka dan 128 Hilang”, https://bnpb.go.id/berita/tim-sargabungan-terus-menemukan-korban-tsunami-selat-sunda-373-meninggal-dunia-1459-luka-luka-dan-128-hilang, diakses 30 Maret 2020. 


\section{Uji Reliabilitas dalam Rehabilitasi Wilayah Pasca Bencana}

Rehabilitasi wilayah pasca bencana termasuk dalam prioritas aksi ke 4 dari SFDRR untuk "membangun kembali lebih baik" suatu kawasan pasca bencana dengan perbaikan dan pemulihan kembali berbagai aspek pemerintahan dan masyarakat dengan tujuan dapat berjalan kembali seperti semula atau lebih baik daripada keadaan sebelumnya dengan melibatkan seluruh unsur, masyarakat maupun swasta negara pada tingkat lokal, nasional, regional dan global. ${ }^{32}$ Kegiatan rehabilitasi mencakup perbaikan lingkungan, perbaikan rumah, pemulihan sosial-ekonomi-budaya, pemulihan pelayanan publik, pemulihan kembali fasilitas pendidikan dengan tujuan agar wilayah tersebut dapat kembali beraktivitas secara normal. ${ }^{33}$ Dalam bagian III tentang Prinsip-Prinsip Panduan huruf k Kerangka Kerja Sendai juga dijelaskan bahwa tahap rehabilitasi bencana menjadi tahap yang cukup kritis untuk dilakukan oleh setiap negara atau pemangku kepentingan dalam mencegah adanya bentuk baru dan mengurangi risiko bencana melalui pembangunan kembali dengan lebih baik serta meningkatkan pendidikan dan kesadaran publik terkait risiko bencana.

Indonesia sebagai negara yang meratifikasi SFDRR menunjukkan komitmennya untuk penanganan bencana terutama rehabilitasi dengan menetapkan Undang-Undang Nomor 24 Tahun 2007 tentang Penanggulangan Bencana dan Peraturan Pemerintah Nomor 21 Tahun 2008 tentang Penyelenggaraan Penanggulangan Bencana. Aturan lainnya yang khusus mengatur rehabilitasi dan rekonstruksi wilayah pasca bencana yaitu Peraturan Kepala BNPB Nomor 17 Tahun 2010 tentang Pedoman Umum Penyelenggaraan Rehabilitasi dan Rekonstruksi Pasca Bencana. Lembaga yang bertanggung jawab dalam penanggulangan bencana Indonesia yaitu Badan Nasional Penanggulangan Bencana (BNPB) dan Badan Penanggulangan Bencana Daerah (BPBD). Selain itu, terdapat dokumen Perencanaan untuk penyelenggaraan rehabilitasi yaitu Rencana Aksi Rehabilitasi dan Rekonstruksi (RENAKSI). RENAKSI adalah dokumen perencanaan untuk kegiatan rehabilitasi dalam periode tertentu oleh BNPB/BPBD bersama Kementerian/

32 Badan Koordinasi Nasional PBP, Pedoman Penanganan Pasca Bencana, Jakarta: Sekretariat Badan Koordinasi Nasional, 2005, hlm. 3.

33 Peraturan Kepala Badan Nasional Penanggulangan Bencana Nomor 11 Tahun 2008 tentang Rehabilitasi dan Rekonstruksi Pasca Bencana, Pasal 3 ayat (3). 
Lembaga serta pemangku kepentingan lainnya ${ }^{34}$ yang memuat kondisi umum suatu wilayah dan kejadian bencana, kondisi korban bencana, kerusakan dan kerugian yang ditimbulkan hingga pengakhiran tugas hingga durasi waktu penyelenggaraan dan standar pelayanan ${ }^{35}$. Terdapat 3 macam bentuk RENAKSI yaitu RENAKSI untuk bencana skala Nasional, skala Provinsi dan skala Kabupaten/Kota. Terakhir, untuk semakin memperkuat implementasi panduan rehabilitasi dalam SFDRR, diatur pula dalam Perka BNPB Nomor 15 Tahun 2011 tentang Pengkajian Kebutuhan Pasca Bencana atau Jitupasna dalam terdapat 5 sektor yang menjadi fokus dalam penanganannya yaitu: (a) Sektor Perumahan Dan Permukiman; (b) Sektor Infrastruktur Publik; (c) Sektor Ekonomi Produktif; (d) Sektor Sosial; dan (e) Lintas Sektor.

\section{Uji Reliabilitas dalam Rehabilitasi KEK Tanjung Lesung}

Uji reliabilitas dalam pembahasan ini dilakukan untuk melihat ketepatan penerapan SFDRR terhadap rehabilitasi KEK Tanjung Lesung oleh pemerintah Indonesia melalui Provinsi Banten dan dinas terkait seperti dinas pariwisata dan BPBD dengan mengemukakan penerapan sesungguhnya yang dilakukan di lapangan.

Uji reliabilitas tersebut dilakukan terhadap sektor infrastruktur, sektor ekonomi produktif, dan sektor sosial. Pertama, dalam sektor infrastruktur mencakup rehabilitasi sarana dan prasarana umum. Rehabilitasi ini meliputi perbaikan jalan akses menuju KEK Tanjung Lesung seperti melakukan perbaikan dan pelebaran jalan seperti Jalan Ruas Pasuruan, Jalan Labuan, Jalan Cibaliung, dan Jalan Pasuruan menuju Tanjung Lesung yang dikoordinasikan oleh Kementerian Pekerjaan Umum dan Perumahan Rakyat (PUPR). ${ }^{36}$ Perbaikan juga dilakukan di Jembatan Citeureup sepanjang $61 \mathrm{~km}$ untuk meningkatkan kemudahan akses menuju KEK Tanjung Lesung serta melakukan penambahan jalan nasional dari Banten menuju ke Tanjung Lesung sepanjang 83,67 km dan jalan tol yang menuju langsung ke arah Tanjung Lesung yaitu tol Serang -

34 Peraturan Kepala BNPB Nomor 17 Tahun 2010 tentang Pedoman Umum Penyelenggaraan Rehabilitasi dan Rekonstruksi Pasca Bencana, Pasal 1 angka 29.

35 Ibid., Pasal 8 ayat (5). Loc. Cit.

36 Badan Penanggulangan Bencana Daerah Kabupaten Pandeglang, Dinas Pariwisata Provinsi Banten, 
Panimbang. ${ }^{37} \mathrm{Hal}$ ini dilakukan agar akses dari Jakarta yang berjarak $170 \mathrm{~km}$ dapat ditempuh selama 2,5 - 3 jam dengan perjalanan darat. Perbaikan dan pembangunan akses jalan di KEK Tanjung Lesung ini diprioritaskan untuk memudahkan akses menuju KEK Tanjung Lesung sehingga dapat menarik kembali minat pengunjung.

Perbaikan juga dilakukan terhadap 102-unit gardu listrik yang padam dan 41-unit lainnya yang rusak pasca terjadinya bencana dan pemulihan serta pembangunan Gardu Listrik Tanjung Lesung dengan kapasitas 2 trafo 2 × 120 MVA (Mega Volt Ampere) yang telah rampung dan beroperasi sejak 24 Oktober $2019^{38}$ yang dikoordinasikan langsung oleh PLN sebagai wujud nyata kontribusi dalam meningkatkan pemenuhan listrik di Banten, terutama kawasan wisata agar dapat melakukan kegiatan pemulihan lainnya dengan baik. Rehabilitasi di KEK Tanjung Lesung juga difokuskan pada pemasangan kembali rambu atau tanda tanda untuk menunjukkan titik-titik berbahaya dan rawan akan bencana. Berdasarkan keterangan dari Kepala Bidang Pencegahan dan Kesiapsiagaan Badan Penanggulangan Bencana Daerah Kabupaten Pandeglang, pemasangan tanda bahaya tersebut telah dilakukan oleh pemerintah maupun pengelola, namun tidak sepenuhnya diperhatikan oleh pengunjung sehingga setelah adanya bencana ini, pemasangan rambu atau tanda tersebut diperbanyak di berbagai titik krusial di KEK Tanjung Lesung tersebut. ${ }^{39}$ Untuk segi keamanan, KEK Tanjung Lesung juga meningkatkan standarnya demi kenyamanan wisatawan dengan memasang teknologi pendeteksi dini tsunami, yaitu WERA Ocean Radar yang mampu mendeteksi adanya tsunami begitu ada gempa besar yang perimeternya sejauh $200 \mathrm{~km} \cdot{ }^{40}$

Kementerian Pariwisata dan Ekonomi Kreatif (KEMENPAREKRAF) melakukan pemantauan terhadap Dinas Pariwisata Provinsi Banten selaku

37 Anna - Berita Satu, "Menengok Proses Tol Serang - Panimbang", https://www.beritasatu.com/ ekonomi/573804-menengok-progres-tol-serangpanimbang, diakses 13 April 2020.

${ }_{38}$ Badan Penanggulangan Bencana Daerah Kabupaten Pandeglang, Dinas Pariwisata Provinsi Banten, Loc. Cit.

39 Wawancara dengan M. Juhriyadi selaku Kepala Bidang Pencegahan dan Kesiapsiagaan Badan Penanggulangan Bencana Daerah Kabupaten Pandeglang, 30 Januari 2020 di Kantor BPBD Kabupaten Pandeglang.

${ }^{40}$ Qalbinur Nawawi-Tribunnews, "Susi Pudjiastuti Kagumi Keindahan Sunset di KEK Tanjung Lesung", https://www.tanjunglesung.com/susi-pudjiastuti-kagumi-keindahan-sunset-di-kek-tanjung-lesung/, diakses 2 April 2020. 
penanggung jawab kegiatan pariwisata di Banten termasuk KEK Tanjung Lesung untuk perbaikan sarana perahu atau kapal milik warga sekitar kawasan KEK Tanjung Lesung yang digunakan sebagai wahana bagi wisatawan. Namun hingga saat ini belum dilakukan perbaikan dermaga yang menjadi tempat bersandar perahu dan kapal yang turut terdampak dari bencana tsunami. Adapun pemulihan terhadap tanggul laut dan pemecah ombak di garis pantai Tanjung lesung juga belum dilakukan sepenuhnya dan masih termasuk dalam 13 Proyek Strategis Nasional (PSN) Banten per Januari 2020 terkait pembangunan KEK Tanjung Lesung dan Tanggul Laut sebagai pendukung kawasan pariwisata. ${ }^{41}$

Kedua, sektor ekonomi produktif yang merupakan sektor terkait dengan pemulihan kawasan agar dapat menarik kembali minat pengunjung ke KEK Tanjung Lesung dan bantuan untuk perekonomian warga sekitar wilayah bencana. KEMENPAREKRAF melalui Dinas Pariwisata Provinsi Banten melakukan berbagai promosi seperti potongan minimal 50\% untuk hotel di KEK Tanjung Lesung bagi wisatawan. ${ }^{42}$ Selain itu, pemerintah juga memberikan bantuan relaksasi keuangan bagi UMKM terdampak di kawasan sekitar Tanjung Lesung berupa penangguhan hutang cicilan bank. Berbagai festival juga turut diselenggarakan seperti Festival Tanjung Lesung pada 27 September 2019 dengan dua acara utama yaitu Rhino Cross Triathlon (lomba renang, balap sepeda dan lari) di Tanjung Lesung dan Mountain Bike Cross Country Marathon. ${ }^{43}$ Dalam festival tersebut terdapat Pasar Kolecer yang berisikan UMKM kuliner, hasil laut, karya seni, hingga buah tangan khas Banten seperti layang-layang yang memiliki berbagai bentuk yang elok. Dan, pada Februari 2020 digelar “Road to Bodur Fest 2020” yang menghadirkan dua komponen acara utama yaitu kuliner dan olahraga. ${ }^{44}$ Loc. Cit.

${ }^{41}$ Badan Penanggulangan Bencana Daerah Kabupaten Pandeglang, Dinas Pariwisata Provinsi Banten, ${ }^{42}$ Ibid.

43 Ghani Nurcahyadi-Media Indonesia, "Festival Tanjung Lesung Sajikan Rhina X-Tri dan Pasar Kolecer", https://mediaindonesia.com/read/detail/260593-festival-tanjung-lesung-sajikan-rhina-x-tri-dan-pasarkolecer, diakses 17 April 2020.

44 Ludhy Cahyana,"Festival Tanjung lesung Dimulai, Bukti Pariwisata Banten Pulih", https:/ / travel.tempo.co/read/1253552/ festival-tanjung-lesung-dimulai-bukti-pariwisata-bantenpulih/full\&view $=$ ok , diakses 2 Maret 2020. 
Ketiga, rehabilitasi dalam sektor sosial dilakukan dengan pemberian Trauma Healing oleh Dinas Kesehatan Provinsi Banten kepada korban bencana ${ }^{45}$ termasuk para wisatawan yang saat itu sedang menghadiri acara musik di KEK Tanjung Lesung pada saat terjadinya tsunami. Selain kesehatan, sektor ini juga memfokuskan pada pendidikan dengan adanya bantuan dari Pemerintah Provinsi Banten dengan memperbaiki bangunan SD atau SMP yang rusak di sekitar KEK Tanjung Lesung serta bantuan seragam dan fasilitas penunjang pendidikan lainnya terutama untuk anak-anak dari pemilik UMKM terdampak di KEK Tanjung Lesung yang diserahkan oleh Gubernur Banten saat itu, Andika Hazrumy. ${ }^{46}$

\section{Penutup}

Berdasarkan uji reliabilitas SFDRR terhadap rehabilitasi KEK Tanjung Lesung pasca tsunami 2018 dapat diketahui bahwa pemerintah Indonesia melalui Provinsi Banten dan dinas terkait seperti dinas pariwisata dan BPBD telah berusaha menerapkannya. Pengujian reliabilitas tersebut menunjukkan bahwa Pemerintah Indonesia telah melakukan panduan penanggulangan bencana sesuai SFDRR dengan sasaran perbaikan yang telah diutamakan dengan baik seperti pada bidang bidang infrastruktur, ekonomi kreatif, dan sosial. Berbagai kegiatan rehabilitasi yang dilakukan baik dari aspek kemanusiaan, perumahan dan pembangunan atau infrastruktur diatur jelas dalam Peraturan Kepala BNPB Nomor 17 Tahun 2010 tentang Pedoman Umum Penyelenggaraan Rehabilitasi dan Rekonstruksi Pasca Bencana. Perbaikan juga dilakukan terhadap fasilitas umum, pemulihan kembali kawasan yang terdampak hingga trauma healing yang diberikan telah sesuai dengan prioritas aksi ke 4 Kerangka Kerja Sendai terkait kesiapsiagaan respon bencana "membangun kembali dengan lebih baik" dan bagian III tentang Prinsip-Prinsip Panduan huruf k terkait rehabilitasi bencana. Sehingga, ketepatan SFDRR dalam rehabilitasi KEK Tanjung Lesung oleh Indonesia dapat dinyatakan telah sesuai dengan panduan yang termuat di dalamnya.

Meskipun demikian, terdapat beberapa masalah yang perlu segera ditangani di lapangan seperti masih adanya kesimpangsiuran koordinasi dan komunikasi

${ }^{45}$ Badan Penanggulangan Bencana Daerah Kabupaten Pandeglang, Dinas Pariwisata Provinsi Banten, Op. Cit.

46 Warta Kota, "Gubernur Banten Berikan Bantuan Sekolah kepada Korban Tsunami Selat Sunda", Gubernur Banten Berikan Bantuan Sekolah Kepada Korban Tsunami Selat Sunda, diakses 2 April 2020. 
antara para pihak yang berkepentingan yaitu antara pemerintah, pengelola KEK Tanjung Lesung, masyarakat sekitar, dan wisatawan. Hal ini bisa diketahui dalam pemasangan papan informasi tanda bahaya di lokasi wisata (KEK Tanjung Lesung) yang belum ada kata sepakat perumusan kata yang tepat antara BPBD Kabupaten Pandeglang, dinas pariwisata, dan pengelola Tanjung Lesung. Selain itu juga belum adanya kesadaran dari masyarakat sekitar untuk tidak mendirikan usaha di lokasi rawan bencana, serta kurangnya pemahaman risiko bencana di tempat wisata bagi para wisatawan. Faktor keamanan-keselamatan dan ekonomi adalah dua hal yang bisa berlawanan di satu sisi, tetapi di sisi lain saling membutuhkan.

Berdasarkan hasil riset, rekomendasi yang diberikan adalah diperlukan pemahaman bersama tentang SFDRR antara para pemangku kepentingan dan juga diperlukan sistem komunikasi-koordinasi yang jelas-terarah mengenai proses rehabilitasi pasca bencana. Selain itu diperlukan kesamaan pandangan tentang pentingnya budaya keamanan dan keselamatan pada saat menjalankan kegiatan perekonomian (pariwisata).

\section{Daftar Pustaka}

\section{Buku}

Badan Koordinasi Nasional PBP, Pedoman Penanganan Pasca Bencana, Sekretariat Badan Koordinasi Nasional, Jakarta, 2005.

Nurmawati, Aprilia, Analisis Pergerakan Magma Gunung Berapi dengan Menggunakan Diagram serta Estimasi Potensi: Volume Magma dengan Menggunakan Data Gravitasi, Universitas Gajah Mada, Yogyakarta, 2013.

Parthiana, I Wayan Hukum Perjanjian Internasional - Bagian I, Mandar Maju, Bandung, 2018.

Peryogawati, Y., Monisme dan Dualisme Hukum Internasional, Fakultas Hukum Universitas Padjajaran, Bandung, 2016.

Sukarmi, dkk, Pengantar Hukum Perjanjian Internasional, UB Press, Malang, 2019.

\section{Jurnal}

Agoes, Etty R, "Hukum Internasional dan Kaitannya dengan Bencana Alam Tsunami", Jurnal Sosiohumaniora Universitas Padjajaran, Vol. 7, No. 2, 2005.

International Strategy for Disaster Reduction, "A Summary Report of the Second Session of The Global Platform for Disaster Risk Reduction", Global Platform for Disaster Risk Reduction Bulletin, Vol. 2, No. 2, 2009. 
Qomarun, "Model Complement and Focus dalam Penanganan Pasca Bencana Tahap Rehabilitasi (Studi Kasus pada Peristiwa Gempa Bumi di Klaten 27 Mei 2006)", Jurnal Warta, Vol. 10, No. 1, 2007.

Puspita, Natalia Yeti, "Tanggung Jawab Negara untuk Menerima Bantuan Kemanusiaan saat Tanggap Darurat Bencana Alam", Jurnal Masalah Masalah Hukum, Jilid 44 No. 22, 2015.

Situngkir, Danel Aditia, "Refleksi Hukum - Terikatnya Negara dalam Perjanjian Internasional", Jurnal Ilmu Hukum Universitas Kristen Satya Wacana, Volume 2, Nomor 2, 2018.

Songko, Gerald E, "Kekuatan Mengikat Perjanjian Internasional Menurut Konvensi Wina Tahun 1969", Lex Privatum, Vol. 4, No. 4, 2016.

\section{Peraturan}

Peraturan Kepala Badan Nasional Penanggulangan Bencana Nomor 11 Tahun 2008 tentang Rehabilitasi dan Rekonstruksi Pasca Bencana.

Peraturan Kepala BNPB Nomor 17 Tahun 2010 tentang Pedoman Umum Penyelenggaraan Rehabilitasi dan Rekonstruksi Pasca Bencana.

Peraturan Kepala BNPB Nomor 15 Tahun 2011 tentang Pengkajian Kebutuhan Pasca Bencana.

Peraturan Pemerintah Nomor 21 Tahun 2008 tentang Penyelenggaraan Penanggulangan Bencana.

Sendai Framework for Disaster Risk Reduction (Kerangka Kerja Sendai untuk Pengurangan Risiko Bencana 2015-2030).

Undang-Undang Nomor 24 Tahun 2007 tentang Penanggulangan Bencana.

Vienna Convention on the Law of Treaties (Konvesi Wina tentang Hukum Perjanjian 1969).

\section{Internet}

Association of Southeast East Asian Nations, "Revised Implementation Plan of the Vision Statement on ASEAN-Japan Friendship and Cooperation: Shared Vision, Shared Identity, Shared Future", https://asean.org/revisedimplementation-plan-visionstatement-asean-japan-friendshipcooperation-shared-vision-shared-identity-sharedfuture-2/, diakses tanggal 21 April 2020.

Badan Nasional Penanggulangan Bencana, "Tim SAR Gabungan Terus Menemukan Korban Tsunami Selat Sunda : 373 Meninggal Dunia, 1.459 Luka-Luka dan 128 Hilang", https://bnpb.go.id/berita/tim-sargabungan-terus-menemukan-korban-tsunami-selat-sunda373-meninggaldunia-1459-luka-luka-dan-128-hilang diakses tanggal 30 Maret 2020.

Ghani Nurcahyadi-Media Indonesia, “Festival Tanjung Lesung Sajikan Rhina XTri dan Pasar Kolecer", https://mediaindonesia.com/read/detail/ 
260593-festival-tanjung lesung-sajikan-rhina-x-tri-dan-pasar-kolecer diakses tanggal 17 April 2020.

Kompas, "Sejak Januari - September 2019, 2.829 Bencana Terjadi di Indonesia", https://nasional.kompas.com/read/2019/10/03/10171591/sejakjanuari-september2019-2829 bencana-terjadi-di-indonesia, diakses tanggal 25 Oktober 2019.

Ludhy Cahyana, "Festival Tanjung lesung Dimulai, Bukti Pariwisata Banten Pulih", https://travel.tempo.co/read/1253552/festival-tanjung-lesungdimulai-buktipariwisata-banten-pulih/full\&view $=$ ok diakses tanggal 2 Maret 2020.

Permanent Mission of the Republic of Indonesia,"Indonesia Berhasil Upayakan Pengakuan Konsep Negara Kepulauan dalam Rangka Kerangan Pengurangan Risiko Bencana"https://mission-indonesia.org/ 2015/03/19/indonesia-berhasil-upayakan-pengakuankonsep-negarakepulauan-dalam-kerangka-pengurangan-resiko-bencana-pbb/diakses tanggal 20 April 2020.

UN Office for Disaster Risk Reduction, "Sendai Framework for Disaster Risk Reduction 2015-2030", https://www.preventionweb.net/sendaiframework/sendai-framework-for-drr diakses tanggal 5 Desember 2019.

Qalbinur Nawawi-Tribunnews, "Susi Pudjiastuti Kagumi Keindahan Sunset di KEK Tanjung Lesung", https://www.tanjunglesung.com/susipudjiastuti-kagumi-keindahan-sunsetdi-kek-tanjung-lesung/ diakses tanggal 2 April 2020.

Warta Kota, “Gubernur Banten Berikan Bantuan Sekolah kepada Korban Tsunami Selat Sunda",https://wartakota.tribunnews.com/2019/01/16/gubernurbanten-berikanbantuan-sekolah-kepada-korban-tsunami-selat-sunda, diakses tanggal 2 April 2020.

\section{Hasil Penelitian}

Dinas Pariwisata Propinsi Banten, Power Point Pengembangan Kawasan Ekonomi Khusus Tanjung Lesung Ditinjau dari Perspektif Pengembangan SDM dan Pariwisata, 2019.

Natalia Yeti Puspita, dkk, "Implementasi Hyogo Framework Action di Indonesia dalam kaitannya dengan mitigasi bencana alam di kawasan Pariwisata (Studi kasus: Mitigasi bencana alam di kawasan wisata pesisir pantai Banten)", Fakultas Hukum dan Fakultas Ilmu Administrasi Bisnis dan Ilmu Komunikasi Unika Atma Jaya Jakarta, Universitas Katolik Indonesia Atma Jaya, 2019.

\section{Wawancara}

Juhriyadi, M., Kepala Bidang Pencegahan dan Kesiapsiagaan Badan Penanggulangan Bencana Daerah Kabupaten Pandeglang, Kantor BPBD Kabupaten Pandeglang, 30 Januari 2020. 


\section{Presentasi atau FGD}

Badan Penanggulangan Bencana Daerah, Dinas Pariwisata Provinsi Banten Pandeglang, Presentasi atau FGD (Forum Group Discussion) terkait Penanganan Bencana akibat Tsunami Selat Sunda di Banten, 30 Januari 2020. 